\title{
Stability of housekeeping genes in alveolar macrophages from COPD patients
}

\author{
T. Ishii*, A.M. Wallace*, X. Zhang*, J. Gosselink*, R.T. Abboud", J.C. English", \\ P.D. Paré* and A.J. Sandford*
}

ABSTRACT: The stability of housekeeping genes is critical when performing gene expression studies. To date, there have been no studies that look at the stability of commonly used housekeeping genes in alveolar macrophages. Expression levels may be affected by culture, stimulation or disease severity.

The present study investigated the expression level of 10 housekeeping genes and analysed the stability of their expression in alveolar macrophages from chronic obstructive pulmonary disease patients $(n=22)$ who were classified according to disease severity.

Guanine nucleotide-binding protein, beta polypeptide 2-like 1 (GNB2L1), hypoxanthine phosphoribosyl transferase 1 (HPRT1) and ribosomal protein L32 (RPL32) were the most stably expressed in alveolar macrophages, irrespective of disease severity. There was no difference in the expression levels of $\mathbf{1 0}$ housekeeping genes between mild and moderate/severe patients. GNB2L1, HPRT1 and RPL32 were also stably expressed in alveolar macrophages cultured with no stimulation, or with interleukin-1ß, lipopolysaccharide or tumour necrosis factor- $\alpha$ stimulation.

In conclusion, as fluctuations in the expression of some housekeeping genes were observed, including glyceraldehyde-3-phosphate dehydrogenase, it is recommended that guanine nucleotide binding protein, beta polypeptide 2-like 1 be used as a reference gene for alveolar macrophages in similar study designs, or that the stability of housekeeping genes be validated in alveolar macrophages prior to expression studies.

KEYWORDS: Alveolar macrophages, chronic obstructive pulmonary disease, housekeeping genes

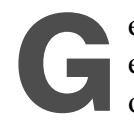
ene expression studies have become extremely important in numerous fields of medical research [1]. In the field of respiratory medicine there have been many investigations into disease pathogenesis utilising quantitative real-time PCR and microarray techniques [2, 3]. In these expression assays, the target concentration in each sample is calculated relative to a nonregulated reference, which is commonly referred to as a housekeeping gene. The result is expressed as a target/reference ratio. Thus, it is extremely important that the expression level of housekeeping genes remain constant under different experimental conditions. It is well known that the expression levels of commonly used housekeeping genes may vary in different cell types, tissues and disease states [4-7].

Alveolar macrophages are thought to be critical in the pathogenesis of several lung diseases, including sarcoidosis, idiopathic lung fibrosis [8], pneumonia [9] and chronic obstructive pulmonary disease (COPD) [10]. Gene expression assays for alveolar macrophages have been performed to investigate their role in pathogenesis [11, 12]. Although it is important to know whether the stability of housekeeping genes in alveolar macrophages is affected by various culture conditions or by differences in the severity of lung disease, these data are currently unavailable. The current authors planned to investigate the association between the expression level of anti-protease genes from alveolar macrophages and the degree of emphysema. Therefore, it was necessary to determine which housekeeping gene is most stable in human alveolar macrophages from the population of COPD patients in order to measure the RNA expression levels of these genes accurately.

The present study investigated the expression level of 10 commonly used housekeeping genes and analysed the stability of their expression in alveolar macrophages from COPD patients who were classified according to disease severity as
AFFILIATIONS

*James Hogg iCAPTURE Centre for Cardiovascular and Pulmonary Research, St. Paul's Hospital, and \# Division of Respiratory Medicine and

'Dept of Pathology, Vancouver General Hospital, University of British Columbia, Vancouver, BC, Canada.

CORRESPONDENCE

A.J. Sandford

James Hogg iCAPTURE Centre for

Cardiovascular and Pulmonary Research

University of British Columbia

St. Paul's Hospital

1081 Burrard Street

Room 166

Vancouver

BC, V6Z 1 Y 6

Canada

Fax: 16048068351

E-mail: asandford@mrl.ubc.ca

Received:

August 032005

Accepted after revision:

November 082005

SUPPORT STATEMENT

This study was supported by funding from the Canadian Institutes of Health Research, GlaxoSmithKline, a Pfizer Fellowship from the Japanese Respiratory Society and a CIHR/ HSFC IMPACT Strategic Training Program Grant in Pulmonary and Cardiovascular Research. A.J. Sandford is the recipient of a Canada Research Chair in genetics and a Michael Smith Foundation for Health Research Scholarship award. 
defined by the Global initiative for chronic Obstructive Lung Disease (GOLD) [13], as well as under various conditions.

\section{MATERIALS AND METHODS Study subjects}

In total, 22 subjects (all Caucasian) who underwent lung resection for a small peripheral tumour at Vancouver General Hospital (Vancouver, BC, Canada) between April 2001 and March 2003 were recruited. This was part of a larger population recruited for a study to investigate the association between the expression level of anti-protease genes in alveolar macrophages and the degree of emphysema.

Pre-operative pulmonary function tests were performed (forced expiratory volume in one second (FEV1) and forced vital capacity (FVC)) and used to categorise the subjects according to the GOLD classification [13].

This study was approved by the University of British Columbia/Providence Health Care and Vancouver Hospital and Health Sciences Research Ethics Boards (all in Canada). All subjects provided written informed consent.

\section{Bronchoalveolar lavage}

The resected lung or lobe was obtained immediately postoperatively and bronchoalveolar lavage (BAL) was performed under sterile conditions within $1 \mathrm{~h}$. A Foley catheter (14 gauge) was inserted into an airway supplying a segment or lobe uninvolved by a tumour. Cold saline was instilled $(60 \mathrm{~mL})$ and BAL fluid was aspirated back. The tissue was gently massaged to help recover the instilled saline. Since this BAL procedure was repeated several times for one subject, aspirated BAL fluid that was collected in sterile plastic bottles was between 240$480 \mathrm{~mL}$ in total. The BAL fluid was filtered through sterile gauze to remove debris and mucus, and the filtrate was then centrifuged $(250 \times g, 10 \mathrm{~min})$.

\section{Alveolar macrophage separation and culture}

Alveolar macrophages were separated by Ficoll-Hypaque density centrifugation as described previously [14]. Cells were washed twice with RPMI 1640 (Invitrogen, Carlsbad, CA, USA) and resuspended in RPMI 1640 at a final concentration of $1 \times 10^{6}$ alveolar macrophages $\cdot \mathrm{mL}^{-1}$. An aliquot of alveolar macrophages was used to determine baseline mRNA levels. Cells were plated onto 6-well plates (Costar, Cambridge, MA, USA) at a density of $4 \times 10^{6}$ cells $\cdot$ well $^{-1}$. Following adherence at $37^{\circ} \mathrm{C}$ in a humidified incubator (95\% air, 5\% $\mathrm{CO}_{2}$ vol/vol) for $2 \mathrm{~h}$, cells were washed twice with RPMI 1640 to remove nonadherent cells before stimulation. Fresh macrophageserum free medium (Invitrogen), supplemented with $2 \mathrm{mM}$ L-glutamine and penicillin-streptomycin (100 U.mL ${ }^{-1}-100$ $\mu \mathrm{g} \cdot \mathrm{mL}^{-1}$; Invitrogen), was added to the adhered cells $(>99 \%$ alveolar macrophages in all cases). Alveolar macrophages were then cultured for a further $24 \mathrm{~h}$ in the presence of: medium alone; medium+lipopolysaccharide (LPS; $2 \mu \mathrm{g} \cdot \mathrm{mL}^{-1}$ ); mediu$\mathrm{m}+$ interleukin (IL)-1 $\beta\left(20 \mathrm{ng} \cdot \mathrm{mL}^{-1}\right)$; or medium+tumour necrosis factor (TNF)- $\alpha\left(20 \mathrm{ng} \cdot \mathrm{mL}^{-1}\right)$. LPS (Escherichia coli) was obtained from Sigma (St. Louis, MO, USA). Recombinant human IL-1 $\beta$ and TNF- $\alpha$ were purchased from R\&D Laboratories (Minneapolis, MN, USA). Cell culture time, stimulants and stimulant concentrations were based on previous work [15-17].

\section{RNA extraction and CDNA synthesis}

Total RNA was isolated from alveolar macrophages using RNeasy ${ }^{\circledR}$ Mini Kit (Qiagen $\mathrm{GmbH}$, Hilden, Germany) according to the manufacturer's protocol. All preparations were treated with RNase-free DNase (Qiagen) to remove genomic DNA. The quantity of RNA was measured with Quant-iT ${ }^{\mathrm{TM}}$ RiboGreen ${ }^{\circledR}$ RNA reagent (Molecular Probes Inc., Eugene, OR, USA). In a total volume of $20 \mu \mathrm{L}, 0.5-1 \mu \mathrm{g}$ of RNA was reverse transcribed in the presence of $200 \mathrm{U}$ SuperScript ${ }^{\circledR}$ RNase Hreverse transcriptase (Invitrogen), $40 \mathrm{U}$ RNaseOUT ${ }^{\circledR}$ recombinant ribonuclease inhibitor (Invitrogen), and $0.5 \mu \mathrm{g}$ Oligo(dT) primer (Invitrogen) according to the manufacturer's instructions.

\section{Quantitative real-time PCR for 10 housekeeping genes}

Approaches to relative quantification with real-time PCR include quantification with external standards and calibratornormalised quantification. Since the latter approach was performed, an external standard for normalisation has not been used in the present study.

Various strategies have been applied to normalise the variation in gene expression including the use of housekeeping genes as a comparator, normalising the number of cells and normalising the quantity of RNA. The present authors chose to measure RNA expression level normalised by the expression level of housekeeping genes; therefore, quantification and standardisation of the amount of cDNA used in the quantitative PCR was not performed.

\section{Design of the primers for 10 housekeeping genes}

The current authors selected 10 commonly used housekeeping genes for the study: abelson murine leukaemia viral oncogene homologue (ABL1); beta-actin (ACTB); beta-2-microglobulin (B2M); glyceraldehyde-3-phosphate dehydrogenase (GAPD); guanine nucleotide-binding protein, beta-peptide 2-like 1 (GNB2L1); hypoxanthine phosphoribosyltransferase 1 (HRPT1); porphobilinogen deaminase (PBGD); ribosomal protein L32 (RPL32); TATA-binding protein (TBP); and betatubulin (TUBB). Gene symbols, gene names, forward and reverse primers and the size of the amplicons are listed in table 1 . The genes were chosen because they have different functions in order to avoid genes belonging to the same biological pathways that may be coregulated, as described in a previous study [18]. All the primers were designed using Primer 3 (available at www-genome.wi.mit.edu/cgi-bin/primer/primer3_www.cgi). Primers spanning at least one intron were chosen to minimise inaccuracies due to genomic DNA contamination. All the primers were synthesised by Sigma.

Conditions for all PCRs were optimised in a PCR Express Thermocycler (Hybaid UK Inc., Ashford, UK), with regard to HotStarTaq ${ }^{\circledR}$ DNA polymerase (Qiagen), forward and reverse primers and various annealing temperatures $\left(55-60^{\circ} \mathrm{C}\right) . \mathrm{PCR}$ amplification products were separated by gel electrophoresis with $2 \%$ UltraPure ${ }^{\circledR}$ Agarose (Invitrogen), including a 100-base pair (bp) DNA ladder (Invitrogen) and analysed with the Eagle Eye $^{\circledR}$ II (Stratagene, La Jolla, CA, USA). The amplified fragments from each primer pair were also purified with a QIAquick ${ }^{\circledR}$ PCR purification Kit (Qiagen) and the sequences of these PCR products were also confirmed by DNA sequencing (University of British Columbia, NAPS Unit, BC, Canada). 
TABLE 1 Primers for real-time PCR

\begin{tabular}{|c|c|c|c|c|c|}
\hline \multirow[t]{2}{*}{ Gene } & & \multirow[t]{2}{*}{ Primers } & \multicolumn{2}{|c|}{ Amplicon size bp } & \multirow[t]{2}{*}{ mRNA accession number } \\
\hline & & & cDNA & genomic DNA & \\
\hline \multirow[t]{2}{*}{ ABL1 } & Forward & TGACAGGGGACACCTACACA & 319 & 5181 & NM_007313 \\
\hline & Reverse & TCAAAGGCTTGGTGGATTTC & & & \\
\hline АСТВ & Forward & CATCGAGCACGGCATCGTCA & 211 & 652 & NM_001101 \\
\hline B2M & Reverse & CCTCCATGATGCTGCTTACA & & & \\
\hline \multirow[t]{2}{*}{ GAPD } & Forward & TGGACCTGACCTGCCGTCTA & 243 & 348 & NM_002046 \\
\hline & Reverse & СССTGTTGCTGTAGCCAAATTC & & & \\
\hline \multirow[t]{2}{*}{ GNB2L1 } & Forward & GAGTGTGGCCTTCTCCTCTG & 224 & 2442 & NM_006098 \\
\hline & Reverse & GCTTGCAGTTAGCCAGGTTC & & & \\
\hline HPRT1 & Forward & GACCAGTCAACAGGGGACAT & 195 & 11952 & NM_000194 \\
\hline \multirow[t]{2}{*}{ RPL32 } & Forward & САTCTCCTTCTCGGCATCA & 154 & & NM_000994 \\
\hline & Reverse & AACCCTGTTGTCAATGCCTC & & & \\
\hline \multirow[t]{2}{*}{ TBP } & Forward & GAACCACGGCACTGATTTTC & 158 & 2760 & NM_003194 \\
\hline & Reverse & ССССАССАТGTTСТGAАTCT & & & \\
\hline \multirow[t]{2}{*}{ TUBB } & Forward & CTTCGGCCAGATCTTCAGAC & 177 & 878 & NM_001069 \\
\hline & Reverse & AGAGAGTGGGTCAGCTGGAA & & & \\
\hline
\end{tabular}

ABL1: abelson murine leukaemia viral oncogene homolog; ACTB: beta-actin; B2M: beta-2-microglobulin; GAPD: glyceraldehyde-3-phosphate dehydrogenase; GNB2L1: guanine nucleotide-binding protein, beta-peptide 2-like 1; HPRT1: hypoxanthine phosphoribosyltransferase 1; PBGD: porphobilinogen deaminase; RPL32: ribosomal protein L32; TBP: TATA-binding protein; TUBB: beta-tubulin.

\section{Real-time PCR}

The expression study was performed using a 384-well plate on an ABI Prism ${ }^{\circledR}$ 7900HT Sequence Detection System (Applied Biosystems, Foster city, CA, USA) with QuantiTect ${ }^{\mathbb{B}}$ SYBR Green PCR Kit (Qiagen). The reactions were performed according to the manufacturer's instructions, with minor modifications.

The following experimental protocol was used: 1) a programme to activate Taq DNA polymerase $\left(95^{\circ} \mathrm{C}\right.$ for $\left.\left.10 \mathrm{~min}\right) ; 2\right)$ an amplification and quantification programme repeated 40 times $\left(94^{\circ} \mathrm{C}\right.$ for $15 \mathrm{~s}, 58^{\circ} \mathrm{C}$ for $30 \mathrm{~s}, 72^{\circ} \mathrm{C}$ for $30 \mathrm{~s}$ with a single fluorescence measurement); and 3) a melting curve programme $\left(58-95^{\circ} \mathrm{C}\right.$ with a heating rate of $2 \%$ and a continuous fluorescence measurement). Dissociation analysis of the PCR products was performed after each run of real-time PCR to confirm lack of nonspecific amplification. Each sample was analysed in triplicate.

\section{Standard curves}

Standard curves were generated from cDNAs made from increasing amounts of total RNA $(0.20,0.60,1.8,5.4$ and $16.2 \mathrm{ng})$. The threshold cycle (CT) was determined with the use of SDS 2.1 software (Applied Biosystems). The CT values were subsequently used to calculate and plot a linear regression line by plotting the logarithm of template concentration (x-axis) against the corresponding threshold cycle (y-axis). The quality of the standard curve can be judged from the slope and the correlation coefficient (r). The slope of the line can be used to determine the efficiency of target amplification (Ex) using the equation:

$$
\operatorname{Ex}=\left(10^{(-1 / \text { slope })}\right)-1
$$

This is a mathematical derivative of:

$$
\mathrm{Xn}=\mathrm{X}_{0} *(1+\mathrm{Ex})^{\mathrm{n}}
$$

where $\mathrm{Xn}$ is number of target molecules at cycle $n, X_{0}$ is initial number of target molecules and $n$ is number of cycles.

Satisfactory amplification plots and linear standard curves were obtained in the assays for all 10 housekeeping genes (data not shown).

Analysis of the expression levels

For the analysis of gene stability, the current authors first calculated gene expression levels normalised only by a calibrator sample (cDNA sample obtained from noncultured alveolar macrophages of a GOLD 0 subject not related to the present study), not by a reference gene. The delta-CT formula for transforming $\mathrm{CT}$ values to relative quantities $(\mathrm{Q})$ was as follows:

$$
\mathrm{Q}=(1+\mathrm{Ex})^{(\text {calibrator CT-sample CT })}
$$

After the analysis of gene stability, these values were normalised with an internal reference, "normalisation factor" (NF) [19], as described below. 
Determination of gene stability and calculation of NF

Gene stability was evaluated using the geNorm software programme (available at www.wzw.tum.de/gene-quantification/) [19]. Briefly, this approach relies on the principle that the expression ratio of two perfect reference genes would be identical in all samples in all experimental conditions or cell types. Variation in the expression ratios between different samples reflects the fact that one, or both, of the genes are not stably expressed. Therefore, increasing variation in this ratio corresponds to decreasing expression stability.

The geNorm programme can be used to calculate the gene expression stability measure $(M)$, which is the mean pair-wise variation for a gene compared with all other tested control genes.

Genes with higher $M$ values have greater variation in expression. The stepwise exclusion of the gene with the highest $M$ value allows the ranking of the tested genes according to their expression stability.

Using the geNorm programme, the NF was also calculated, which has been reported to be a more accurate internal control than one housekeeping gene [19]. The present study calculated $\mathrm{NF}$ as a geometric mean of the expression of the three most stable housekeeping genes.

By dividing the relative quantities by the NF, the expression level of all 10 genes in the samples was calculated.

\section{Statistical analysis}

Results are presented as mean (SD). Comparisons were made by paired or unpaired t-tests. These analyses were performed with the JMP 5.1 programme (SAS Institute Inc., Cary, NC, USA). A p-value $<0.05$ was considered significant.

\section{RESULTS}

\section{Characteristics of the subjects}

The characteristics for the subjects stratified by GOLD stages are shown in table 2. The subjects in the GOLD 1-4 group were

\begin{tabular}{|c|c|c|}
\hline \multirow[t]{3}{*}{ TABLE 2} & \multicolumn{2}{|c|}{$\begin{array}{l}\text { Characteristics of subjects stratified by Global } \\
\text { initiative for chronic Obstructive Lung Disease } \\
\text { (GOLD) stage }\end{array}$} \\
\hline & \multicolumn{2}{|c|}{ GOLD Stage } \\
\hline & 0 & $1-4$ \\
\hline Subjects $n$ & 10 & $12^{\#}$ \\
\hline Age yr & $71.0(5.4)$ & $62.2(9.7)^{\star}$ \\
\hline Males \% & 50 & 50 \\
\hline Pack-yrs & $42.8(10.7)$ & $55.2(34.9)$ \\
\hline FVC L & $3.4(1.2)$ & $3.2(1.0)$ \\
\hline FEV $_{1} \mathrm{~L}$ & $2.5(0.9)$ & $1.8(0.8)$ \\
\hline FEV $1 \%$ predictec & $90.0(13.1)$ & $64.8(23.6)^{\star *}$ \\
\hline FEV $1 /$ FVC $\%$ & $76.9(7.5)$ & $55.4(11.8)^{\star \star}$ \\
\hline
\end{tabular}

Data are presented as mean (SE), unless otherwise stated. FVC: forced vital capacity; FEV 1 : forced expiratory volume in one second. ${ }^{\#}$ : GOLD $1, \mathrm{n}=4$; GOLD 2, n=4; GOLD 3, $n=3$; GOLD 4, $n=1$. *: $p<0.05$; **: $p<0.01$, compared with GOLD 0 subjects. younger than those of the GOLD 0 group. For the pulmonary function tests, FEV1 \% predicted and FEV1/FVC were significantly lower in the GOLD 1-4 group than in the GOLD 0 group as expected. There was no difference in pack-yrs between the two groups.

\section{Stability of housekeeping genes in alveolar macrophages}

The expression level of 10 housekeeping genes (table 1) with the QuantiTect SYBR Green (Qiagen) method was investigated, as described previously [18].

The expression stabilities of the 10 housekeeping genes were evaluated using the geNorm software as described in the Materials and methods section. As shown in table 3, GNB2L1, HPRT1 and RPL32 were the most stably expressed in alveolar macrophages from GOLD 0 subjects in noncultured cells and also in culture without stimulation or with IL-1 $\beta$, LPS or TNF- $\alpha$ stimulation. TBP and ABL1 were the least stably expressed under these conditions.

\section{Effect of differences in the severity of COPD on stability of housekeeping genes}

The effect of differences in the severity of COPD on stability of the housekeeping genes was investigated. As in the above mentioned results for the GOLD 0 subjects, in GOLD 1-4 subjects, GNB2L1, HPRT1 and RPL32 were the most stably expressed, and TBP and ABL1 were the least stably expressed when uncultured (table 3).

The present authors then compared the expression levels of the housekeeping genes between GOLD 0 and GOLD 1-4 patients. The expression levels were normalised by the NF calculated from the expression level of the three most stable genes (GNB2L1, HPRT1 and RPL32) as described in the Materials and Methods section. There was no difference in the expression levels of the 10 housekeeping genes between GOLD 0 and GOLD 1-4 patients (fig. 1).

\section{IL-1及, LPS and TNF- $\alpha$ affect expression level of some housekeeping genes}

The current study also investigated fluctuations in expression of the 10 housekeeping genes in alveolar macrophages cultured with no stimulation, or stimulated with IL-1 $\beta$, LPS or TNF- $\alpha$. There were some fluctuations in the expression level of these genes in certain conditions; the expression levels of a representative subset of these genes are shown in figure 2 .

In culture (without stimulation) compared with noncultured, the expression levels of most of the genes were increased, except for RPL32 and GNB2L1.

With IL-1 $\beta$ stimulation, the expression level of GAPD increased and that of B2M and RPL32 decreased. With LPS stimulation, the expression level of B2M, GAPD, HPRT1, TBP and TUBB increased and that of PBGD and RPL32 decreased. When stimulated with TNF- $\alpha$, the expression level of GAPD and GNB2L1 increased, but HPRT1 and TUBB decreased.

\section{DISCUSSION}

It is generally recommended that the stability of housekeeping genes be validated prior to expression studies [4]. There are some reports of the expression levels of housekeeping genes in various cells and tissues [5, 20], and also of the methods used 
TABLE 3 Control genes ranked in order of their expression stability

GOLD 0

\begin{tabular}{|c|c|c|c|c|c|}
\hline \multirow{2}{*}{$\begin{array}{l}\text { Not cultured } \\
\text { No stimulation }\end{array}$} & \multicolumn{4}{|c|}{ Cultured } & \multirow{2}{*}{\begin{tabular}{|l} 
Not cultured \\
No stimulation
\end{tabular}} \\
\hline & No stimulation & With IL-1 & With LPS & With TNF & \\
\hline TBP & ABL1 & ABL1 & ABL1 & ABL1 & TBP \\
\hline ABL1 & TBP & TBP & TBP & TBP & ABL1 \\
\hline TUBB & TUBB & TUBB & PBGD & TUBB & TUBB \\
\hline GAPD & PBGD & B2M & B2M & PBGD & ACTB \\
\hline B2M & GAPD & GAPD & GAPD & GAPD & B2M \\
\hline RPL32 & HPRT1 & HPRT1 & RPL32 & HPRT1 & HPRT1 \\
\hline HPRT1-GNB2L1 & GNB2L1-RPL32 & GNB2L1-RPL32 & HPRT1-GNB2L1 & GNB2L1-RPL32 & GNB2L1-RPL32 \\
\hline
\end{tabular}

GOLD: Global initiative for chronic Obstructive Lung Disease; IL: interleukin; LPS: lipopolysaccharide; TNF: tumour necrosis factor; TBP: TATA-binding protein; ABL1: abelson murine leukaemia viral oncogene homologue; TUBB: beta-tubulin; PBGD: porphobilinogen deaminase; ACTB: beta-actin; GAPD: glyceraldehyde-3-phosphate dehydrogenase; B2M: beta-2-microglobulin; RPL32: ribosomal protein L32; HPRT1: hypoxanthine phosphoribosyltransferase 1; GNB2L1: guanine nucleotide-binding protein, beta-peptide 2-like 1. \#: stability increasing from top to bottom. The two most stable control genes in each condition, for example HPRT1 and GNB2L1 in GOLD 0 not cultured, cannot be ranked in order because of the required use of gene ratios for gene-stability measurements.

to analyse the stability of these genes [19]. However, to date there are no studies in the literature showing which housekeeping genes are the most stable in human alveolar macrophages. Since gene expression studies of lung tissue [2, $3]$, and specifically alveolar macrophages, are frequent and

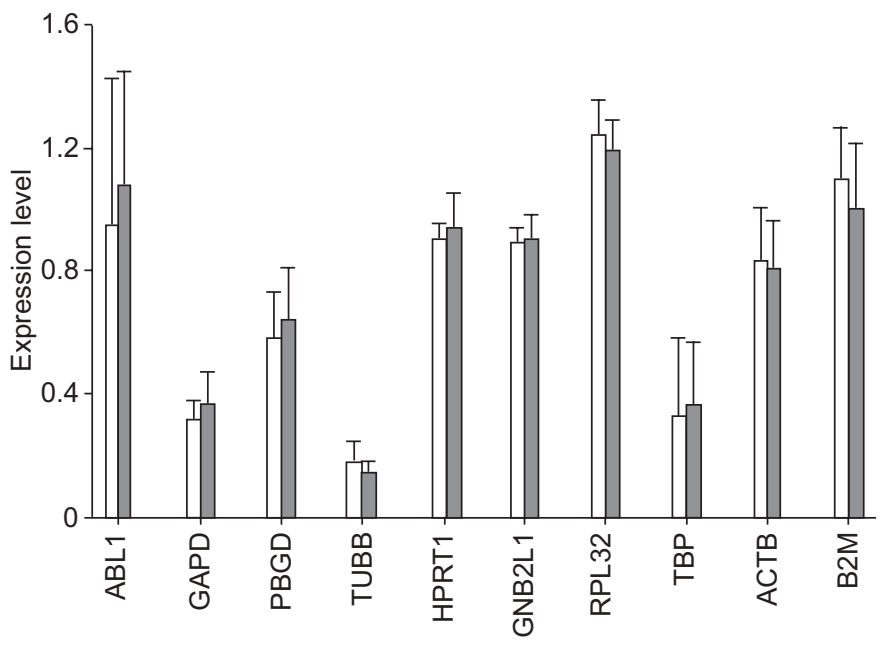

FIGURE 1. The expression levels of 10 housekeeping genes between GOLD 0 $(\square)$ and GOLD 1-4 (回) subjects. The expression level of the 10 housekeeping genes (ABL1: abelson murine leukaemia viral oncogene homologue; GAPD: glyceraldehyde-3-phosphate dehydrogenase; PBGD: porphobilinogen deaminase; TUBB: beta-tubulin; HPRT1: hypoxanthine phosphoribosyltransferase 1; GNB2L1: guanine nucleotide-binding protein, beta-peptide 2-like 1; RPL32: ribosomal protein L32; TBP: TATA-binding protein; ACTB: beta-actin; and B2M: beta-2-microglobulin) was normalised by the normalisation factor calculated from the expression level of the three most stable genes (GNB2L1, HPRT1 and RPL32). No difference was observed in the expression levels of these genes between the two groups. Data are presented as mean (SD). potentially very informative, the selection of appropriate housekeeping gene(s) is critical.

In the present study, GNB2L1, HPRT1 and RPL32 were the most stably expressed genes in alveolar macrophages from the subjects of all GOLD stages in noncultured cells and also in culture with or without stimulation by IL-1 $\beta$, LPS or TNF- $\alpha$.

GNB2L1, also known as the receptor for activated C-kinase [21, $22]$, is an intracellular receptor for protein kinase $C$, a constituent of the ribosome [23] and has been recommended as a housekeeping gene $[20,24]$. Although the expression of HPRT1 and RPL32 was changed by cell culture and also by LPS stimulation, the expression level of GNB2L1 was not changed under cultured conditions (without stimulation) compared with noncultured conditions, although there was a slight change when cultured with TNF- $\alpha$. Thus, the current authors found that GNB2L1 was the most stable housekeeping gene of alveolar macrophages and recommend its use in similar studies. However, even the three most stable genes show variations under different conditions which underscore the importance of using multiple reference genes in studies of gene expression.

It is now well documented that GAPD mRNA levels vary under some experimental conditions [25], and its mRNA levels are highly heterogeneous even in cellular subpopulations of the same tissue origin [26]. BUSTIN [27] reported that for most experimental conditions its use is inappropriate and should be discontinued. The present authors observed that the expression level of GAPD was not stable via analysis with the geNorm software, and that its expression was substantially changed by culture and by all of the stimuli used in the study. Thus, the current findings suggest that GAPD should not be used as a reference gene for alveolar macrophage studies of similar design. The use of ribosomal 18s RNA was recommended in the quantitative comparison of mRNA levels in 

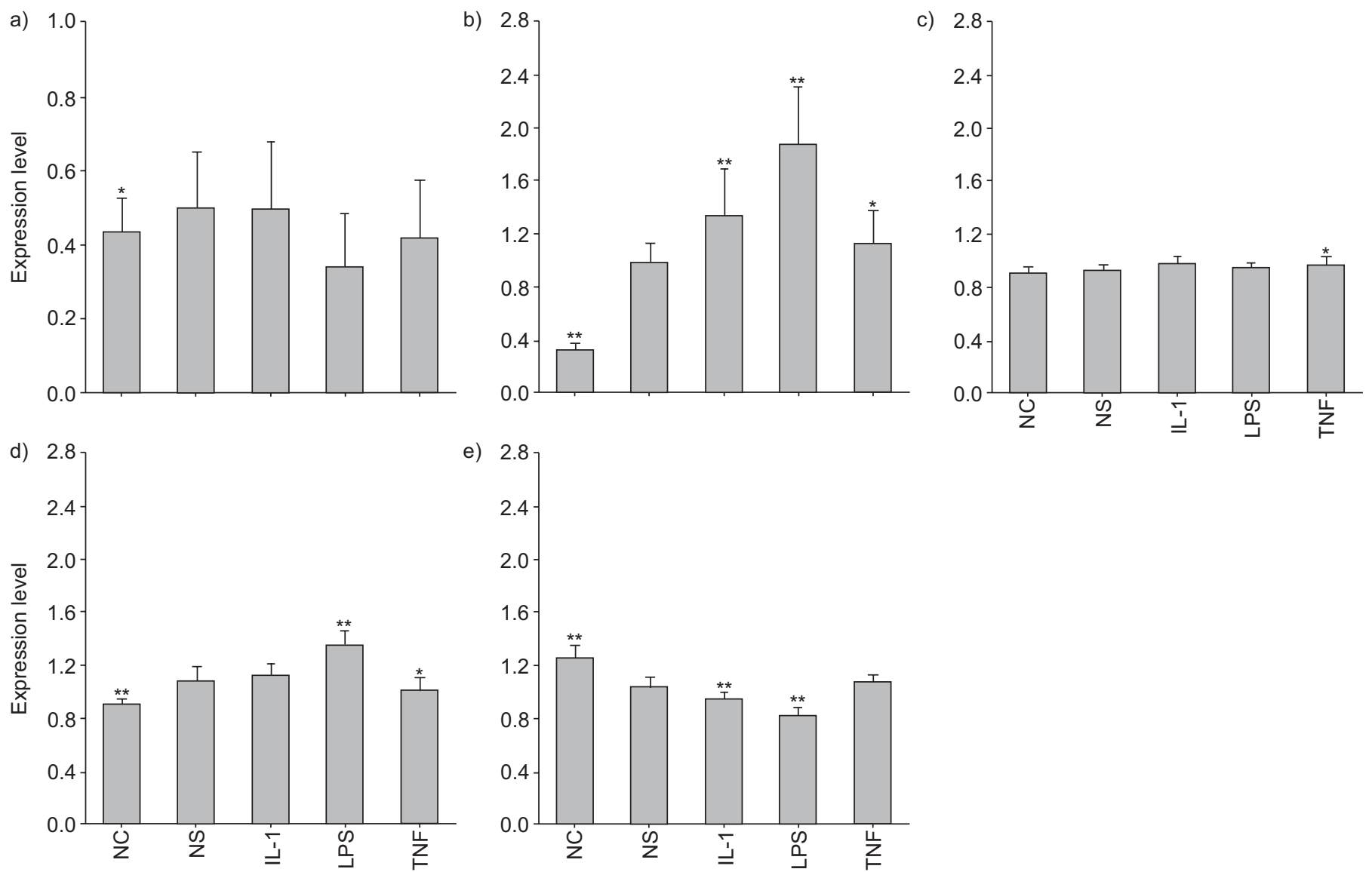

FIGURE 2. Expression levels of a representative subset of 10 genes. a) Beta-actin (ACTB), b) glyceraldehyde-3-phosphate dehydrogenase (GAPD), c) guanine nucleotide-binding protein, beta-peptide 2-like 1 (GNB2L1), d) hypoxanthine phosphoribosyltransferase 1 (HPRT1), and e) ribosomal protein L32 (RPL32). The expression level was normalised by the normalisation factor calculated from the expression level of the three most stable genes (GNB2L1, HPRT1 and RPL32). HPRT1 was among the most stable genes per condition as shown in table 3, although expression was changed by cell culture and also by lipopolysaccharide (LPS) stimulation. The expression of GAPD was strongly changed by culture or by all stimulations and was less stable than ACTB, which is frequently used as a housekeeping gene. NC: not cultured; NS: no stimulation; IL: interleukin; TNF: tumour necrosis factor. ${ }^{*}: p<0.05$; ${ }^{*}: p<0.01$, compared with the expression level in the cells cultured with NS.

invasive and noninvasive human melanoma cell subpopulations instead of GAPDH and ACTB [26]. While the use of ribosomal 18s RNA is one option for normalisation, its level can vary between individuals and between samples from the same individual [28]. In addition, methodological issues over the use of random primers in the reverse transcription reaction complicate the use of 18s RNA as a reference [29]. Therefore, the current authors, as well as WONG and MEDRANo [30], consider that validation of a panel of candidate reference genes is the optimal approach for gene expression studies.

The current results indicate that there was no difference in the expression level of the 10 housekeeping genes between GOLD 0 and GOLD 1-4 patients. In a study of human asthma, where target gene expression between experimental groups appeared different when ACTB was used as a housekeeping gene, the results were misleading because it was in fact the ACTB, rather than the target gene, that changed [31]. However, from the present data, all 10 housekeeping genes were unaffected by the severity of COPD and could be used as housekeeping genes if disease severity was the only difference between the experimental groups. The expression levels and the stability of the housekeeping genes in macrophages isolated from individuals with lung diseases other than COPD have not been examined, which is also important and remains to be elucidated.

In conclusion, guanine nucleotide-binding protein, betapeptide 2-like 1, hypoxanthine phosphoribosyltransferase 1 and ribosomal protein L32 were the most stably expressed genes in alveolar macrophages from all Global initiative of chronic Obstructive Lung Disease stages in: noncultured cells, culture with no stimulation, interleukin- $1 \beta$, lipopolysaccharide, or tumour necrosis factor- $\alpha$ stimulation. Thus, these are good reference genes for quantitative real-time PCR studies. Since the current study also observed fluctuations in expression in frequently used housekeeping genes, including glyceraldehyde-3-phosphate dehydrogenase with various stimulations, it is recommend that guanine nucleotide-binding protein, beta-peptide 2-like 1 be used as a housekeeping gene for alveolar macrophages in studies of similar design and that the stability of housekeeping genes be validated prior to expression studies. 


\section{REFERENCES}

1 Bassett DE Jr, Eisen MB, Boguski MS. Gene expression informatics-it's all in your mine. Nat Genet 1999; 21: Suppl. $1,51-55$.

2 Golpon HA, Coldren DC, Zamora MR, et al. Emphysema lung tissue gene expression profiling. Am J Respir Cell Mol Biol 2004; 31: 595-600.

3 Ning W, Li CJ, Kaminski N, et al. Comprehensive gene expression profiles reveal pathways related to the pathogenesis of chronic obstructive pulmonary disease. Proc Natl Acad Sci USA 2004; 101: 14895-14900.

4 Thellin O, Zorzi W, Lakaye B, et al. Housekeeping genes as internal standards: use and limits. J Biotechnol 1999; 75: 291-295.

5 Warrington JA, Nair A, Mahadevappa M, Tsyganskaya M. Comparison of human adult and fetal expression and identification of 535 housekeeping/maintenance genes. Physiol Genomics 2000; 2: 143-147.

6 Bustin SA. Absolute quantification of mRNA using realtime reverse transcription polymerase chain reaction assays. J Mol Endocrinol 2000; 25: 169-193.

7 Suzuki T, Higgins PJ, Crawford DR. Control selection for RNA quantitation. Biotechniques 2000; 29: 332-337.

8 Lohmann-Matthes ML, Steinmüller C, Franke-Ullmann G. Pulmonary macrophages. Eur Respir J 1994; 7: 1678-1689.

9 Delclaux C, Azoulay E. Inflammatory response to infectious pulmonary injury. Eur Repir J 2003; 22: Suppl. 42, 10s-14s.

10 Shapiro SD. The macrophage in chronic obstructive pulmonary disease. Am J Respir Crit Care Med 1999; 160: Suppl. 5 Pt 2, S29-S32.

11 Suzuki K, Suda T, Naito T, Ide K, Chida K, Nakamura H. Impaired toll-like receptor 9 expression in alveolar macrophages with no sensitivity to CpG DNA. Am J Respir Crit Care Med 2005; 171: 707-713.

12 Barber R, Baillie GS, Bergmann R, et al. Differential expression of PDE4 cAMP phosphodiesterase isoforms in inflammatory cells of smokers with COPD, smokers without COPD, and nonsmokers. Am J Physiol Lung Cell Mol Physiol 2004; 287: L332-L343.

13 Pauwels R, Buist A, Calverley P, Jenkins C, Hurd S. Global strategy for the diagnosis, management, and prevention of chronic obstructive pulmonary disease. NHLBI/WHO global initiative for chronic obstructive lung disease (GOLD) workshop summary. Am J Respir Crit Care Med 2001; 163: 1256-1276.

14 Boyum A. Isolation of mononuclear cells and granulocytes from human blood. Isolation of monuclear cells by one centrifugation, and of granulocytes by combining centrifugation and sedimentation at $1 \mathrm{~g}$. Scand J Clin Lab Invest 1968; 97: 77-89.

15 Senior RM, Connolly NL, Cury JD, Welgus HG, Campbell EJ. Elastin degradation by human alveolar macrophages. A prominent role of metalloproteinase activity. Am Rev Respir Dis 1989; 139: 1251-1256.

16 Shapiro SD, Campbell EJ, Kobayashi DK, Welgus HG. Immune modulation of metalloproteinase production in human macrophages. Selective pretranslational suppression of interstitial collagenase and stromelysin biosynthesis by interferon-gamma. J Clin Invest 1990; 86: 1204-1210.
17 Strieter RM, Chensue SW, Basha MA, et al. Human alveolar macrophage gene expression of interleukin- 8 by tumor necrosis factor-alpha, lipopolysaccharide, and interleukin1 beta. Am J Respir Cell Mol Biol 1990; 2: 321-326.

18 Zhang X, Ding L, Sandford A. Selection of reference genes for gene expression studies in human neutrophils by realtime PCR. BMC Mol Biol 2005; 6: 4-10.

19 Vandesompele J, De Preter K, Pattyn F, et al. Accurate normalization of real-time quantitative RT-PCR data by geometric averaging of multiple internal control genes. Genome Biol 2002; 3: RESEARCH0034.

20 Hsiao LL, Dangond F, Yoshida T, et al. A compendium of gene expression in normal human tissues. Physiol Genomics 2001; 7: 97-104.

21 Guillemot F, Billault A, Auffray C. Physical linkage of a guanine nucleotide-binding protein-related gene to the chicken major histocompatibility complex. Proc Natl Acad Sci USA 1989; 86: 4594-4598.

22 Ron D, Chen CH, Caldwell J, Jamieson L, Orr E, MochlyRosen D. Cloning of an intracellular receptor for protein kinase C: a homolog of the beta subunit of G proteins. Proc Natl Acad Sci USA 1994; 91: 839-843.

23 Nilsson J, Sengupta J, Frank J, Nissen P. Regulation of eukaryotic translation by the RACK1 protein: a platform for signalling molecules on the ribosome. EMBO Rep 2004; 5: 1137-1141.

24 Eisenberg E, Levanon EY. Human housekeeping genes are compact. Trends Genet 2003; 19: 362-365.

25 Zhu G, Chang Y, Zuo J, et al. Fudenine, a C-terminal truncated rat homologue of mouse prominin, is blood glucose-regulated and can up-regulate the expression of GAPDH. Biochem Biophys Res Commun 2001; 281: 951-956.

26 Goidin D, Mamessier A, Staquet MJ, Schmitt D, BerthierVergnes O. Ribosomal 18S RNA prevails over glyceraldehyde-3- phosphate dehydrogenase and betaactin genes as internal standard for quantitative comparison of mRNA levels in invasive and noninvasive human melanoma cell subpopulations. Anal Biochem 2001; 295: 17-21.

27 Bustin SA. Quantification of mRNA using real-time reverse transcription PCR (RT-PCR): trends and problems. J Mol Endocrinol 2002; 29: 23-39.

28 Tricarico C, Pinzani P, Bianchi S, et al. Quantitative realtime reverse transcription polymerase chain reaction: normalization to rRNA or single housekeeping genes is inappropriate for human tissue biopsies. Anal Biochem 2002; 309: 293-300.

29 Zhang J, Byrne CD. Differential priming of RNA templates during cDNA synthesis markedly affects both accuracy and reproducibility of quantitative competitive reversetranscriptase PCR. Biochem J 1999; 337: 231-241.

30 Wong ML, Medrano JF. Real-time PCR for mRNA quantitation. Biotechniques 2005; 39: 75-85.

31 Glare EM, Divjak M, Bailey MJ, Walters EH. $\beta$-Actin and GAPDH housekeeping gene expression in asthmatic airways is variable and not suitable for normalizing mRNA levels. Thorax 2002; 57: 765-770. 